\title{
Polipose Juvenil: Relato de 2 Casos
}

\author{
Juvenile Polyposis: Case two Report
}

\author{
JUVENALDAROCHATORRES NETO ${ }^{1}$, RODRIGO ROCHA SANTIAGO $^{2}$, ANACAROLINALISBOAPRUDENTE $^{3}$, DAN \\ RODRIGUES MARIANO ${ }^{4}$, HUGO LEITE DE FARIAS BRITO ${ }^{5}$, FELIPEAUGUSTO DO PRADO TORRES ${ }^{6}$, JÚLIO \\ AUGUSTO DO PRADO TORRES ${ }^{7}$, FERNANDA MENDONÇARAMOS $^{8}$, RAQUEL MATOS DE SANTANA $^{9}$
}

\author{
${ }^{1}$ Professor, doutor e chefe do Serviço de Coloproctologia da UFS, ${ }^{2}$ Médico coloproctologista e chefe \\ da residência médica de Cirurgia Geral da UFS, ${ }^{3}$ Professora substituta do Serviço de Coloproctologia da UFS, \\ ${ }^{4}$ Residente de Coloproctologia da UFS, ${ }^{5}$ Professor adjunto e chefe do serviço de Patologia da UFS, \\ ${ }^{6,7,8,9}$ Acadêmicos de Medicina da UFS.
}

\begin{abstract}
TORRES NETO JR; SANTIAGO RR; PRUDENTE ACL; MARIANO DR; BRITO HLF; TORRES FAP; TORRES JAP; RAMOS FM; SANTANA RM. Polipose Juvenil: Relato de 2 Casos. Rev bras Coloproct, 2010;30(2): 221-227.

RESUMO: A Polipose Juvenil é uma afecção rara e faz parte do grupo das poliposes hamartomatosas familiares (PHF). É uma síndrome autossômica dominante que pode ser desencadeada por mutações no gene SMAD4/DPC4 (que codifica um sinalizador intermediário de TGF- $\beta$ ). Caracteriza-se pelo aparecimento de 10 ou mais pólipos hamartomatosos (juvenis) no trato gastrintestinal, predominando no cólon. Costuma manifestar-se entre 4 e 14 anos de idade. Alguns pólipos adquirem focos adenomatosos apesar da natureza hamartomatosa das lesões e há chance de malignização. Relato de $\mathbf{2}$ casos de pacientes portadores de Polipose Juvenil colônica associada a focos de adenoma com displasia e revisão da literatura.
\end{abstract}

Descritores: Polipose juvenil, malignização, herança familiar.

\section{INTRODUÇÃO}

Os pólipos juvenis únicos são lesões hamartomatosas focais do epitélio mucoso e da lâmina própria. Apresentam-se geralmente em número de um a três em cada paciente e afetam aproximadamente $1 \%$ das crianças menores de 10 anos. Pólipos hamartomatosos isolados podem ser identificados no cólon de adultos; são lesões incidentais, referidas como pólipos de retenção. Em ambos os grupos etários, cerca de $80 \%$ dos pólipos ocorrem no reto, mas podem estar espalhados pelo cólon ${ }^{(1)}$.

Pólipos juvenis costumam ser grandes (1 a 3 $\mathrm{cm}$ de diâmetro), redondos, lisos ou discretamente lobulados, com hastes que podem ter $2 \mathrm{~cm}$ de comprimento enquanto que os pólipos de retenção costumam ser menores $(<1 \mathrm{~cm} \text { de diâmetro })^{(1)}$.
A polipose juvenil, por sua vez, é afecção mais rara e faz parte do grupo das poliposes hamartomatosas familiares (PHF). É uma síndrome autossômica dominante que pode ser desencadeada por mutações no gene SMAD4/DPC4 (que codifica um sinalizador intermediário de TGF- $\beta)^{(1)}$. Caracteriza-se pelo aparecimento de 10 ou mais pólipos juvenis no trato gastrintestinal, predominando no cólon. Costuma se manifestar entre 4 e 14 anos de idade ${ }^{(2)}$. Alguns pólipos adquirem focos adenomatosos apesar da natureza hamartomatosa das lesões e há chance de malignização. Além disso, por ser decorrente de uma alteração genética, a herança familiar é positiva em muitos casos.

O diagnóstico desta síndrome pode ser feito por enema opaco, retossigmoidoscopia e/ou colonoscopia seguida do exame anatomopatológico dos pólipos encontrados. As polipectomias seriadas por via

Trabalho realizado no Serviço de Coloproctologia e Serviço de Patologia do Hospital Universitário da Universidade Federal de Sergipe (HU/UFS) - Aracaju - SE - Brasil. 
colonoscópica permitem a exérese do maior número de pólipos possíveis, a fim de afastar eventuais lesões adenomatosas ou displásicas, além de fazer regredir as manifestações clínicas ${ }^{(3)}$. O tratamento é cirúrgico e agressivo - colectomia total ou proctocolectomia total restaurativa com bolsa ileal se o reto estiver muito acometido.

\section{RELATO DE 2 CASOS}

\section{Caso 1}

S.A.A., gênero feminino, 24 anos, estudante, relata que aos 7 anos de idade procurou o serviço médico (em São Paulo) devido a dores abdominais, sangramento retal e exteriorização de tumorações ao defecar. O médico solicitou uma colonoscopia e diagnosticou Polipose Juvenil (sic). Não foi realizado nenhum procedimento médico ou prescrito qualquer medicamento devido à idade da paciente na época. A paciente continuou a exteriorizar os pólipos ao defecar sem nenhum outro sintoma associado durante os 7 anos seguintes.

Aos 14 anos de idade (1999) procurou o Hospital das Clínicas (SP) para acompanhamento do caso, foi submetida a uma nova colonoscopia e polipectomia dos pólipos retais. Nos 3 anos seguintes à polipectomia, a paciente permaneceu assintomática. Aos 17 anos de idade, a mesma refere recidiva do prolapso dos pólipos do reto, mas não procurou atendimento médico.

Há 4 meses a paciente (já residente em Sergipe) procurou o Serviço de Coloproctologia do Hospital Universitário (HU/UFS) de Aracaju. Foi submetida a uma nova colonoscopia que evidenciava pólipos no cólon e reto e foi realizada polipectomia subseqüente (Figura 1). O material retirado foi encaminhado para avaliação anatomopatológica.

O exame anatomopatológico foi realizado e o diagnóstico inicial foi de adenoma serrilhado com displasia de alto grau (5 fragmentos) e adenoma serrilhado com displasia de baixo grau (2 fragmentos) em mucosa retal. Revisão posterior das lâminas demonstrou que $\mathrm{o}$ aspecto histológico era consistente com alteração adenomatosa em pólipos do tipo juvenil (Figura 2).

A paciente relata que após a última polipectomia não houve episódio de exteriorização de pólipos ao defecar e nenhum outro sintoma associado. Após a análise do laudo anatomopatológico que evidenciou pólipo juvenil com componente adenomatoso e displasia de

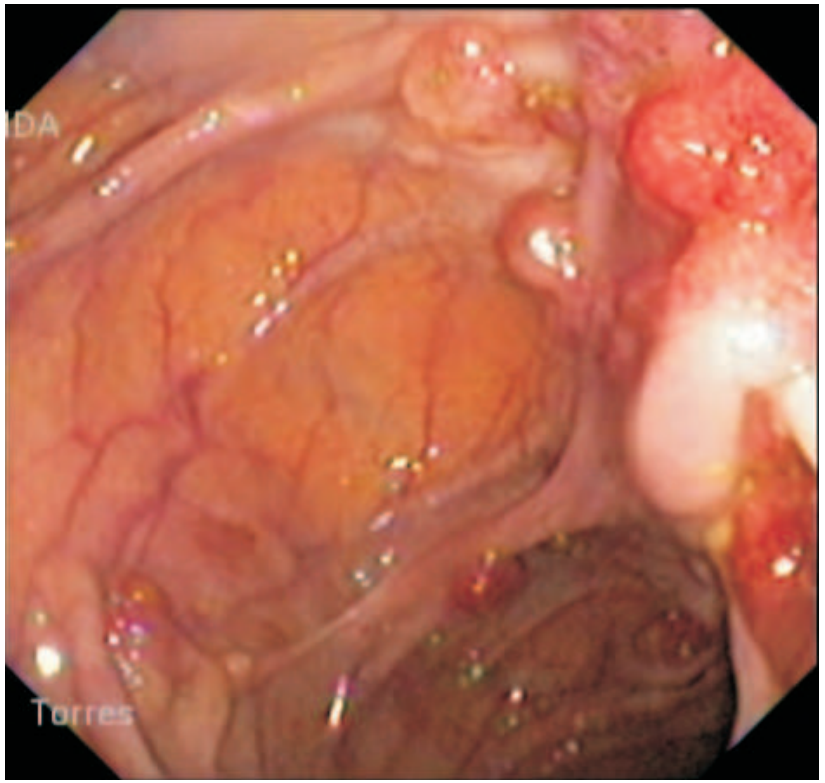

Figura 1 - Colonoscopia da paciente 1 mostrando múltiplos pólipos sésseis e pediculados no ceco.

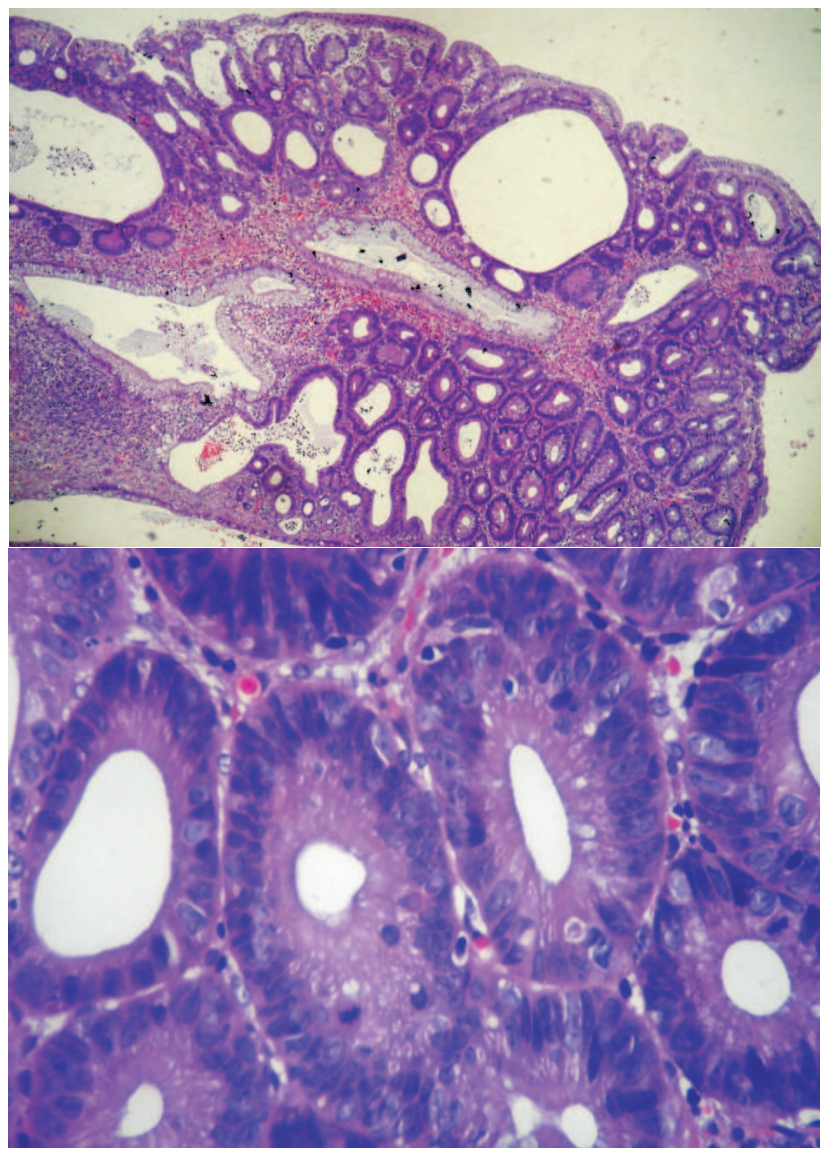

Figura 2 - Microscopia de um dos pólipos excisado durante a colonoscopia da paciente 1. Em menor aumento, pólipo juvenil característico com numerosas glândulas cisticamente dilatadas. Em maior aumento, displasia do epitélio glandular com núcleos hipercrômicos dispostos em paliçada e figuras de mitose. 
alto grau, o diagnóstico de Polipose Juvenil foi confirmado e concluiu-se que seria necessária a realização de proctocolectomia total restaurativa com anastomose íleo-anal com bolsa ileal.

Antecedentes familiares: mãe, dois tios maternos e um primo portadores de Polipose Juvenil; a mãe e um dos tios foram submetidos à colectomia total; e o outro tio portador de Polipose faleceu aos 45 anos de idade de câncer de cólon por não aceitar submeter-se à cirurgia proposta.

No dia 06 de outubro de 2008 no Hospital Universitário de Aracaju (HU/UFS), a paciente foi submetida à proctocolectomia total restaurativa videolaparoscópica com anastomose íleo-anal e bolsa ileal em J com ileostomia protetora. A peça cirúrgica (Figura 3) foi encaminhada para avaliação anatomopatológica.

A cirurgia teve duração de 8 horas e 40 minutos sem intercorrências, sendo transfundidos 2 concentrados de hemácias. Evolução pós-operatória satisfatória com tentativa de realimentação no $2^{\circ}$ dia pós-operatório (DPO), interrompida pela presença de vômitos. A realimentação foi regularizada apenas no $7^{\circ} \mathrm{DPO}$. Teve alta no $11^{\circ} \mathrm{DPO}$, com bom estado geral e ileostomia funcionante.

No dia 23 de outubro de 2008, a paciente compareceu à consulta de acompanhamento no ambulatório de coloproctologia do HU e apresentava-se em bom estado geral, com ileostomia funcionante e sem queixas.

O exame anatomopatológico da peça cirúrgica (intestino grosso + íleo terminal) foi realizado com o achado de: múltiplos pólipos do tipo juvenil (50 lesões) em mucosa colônica e retal; presença de áreas de displasia epitelial de baixo grau em 11 pólipos do tipo juvenil; presença de adenomas tubulares com displasia

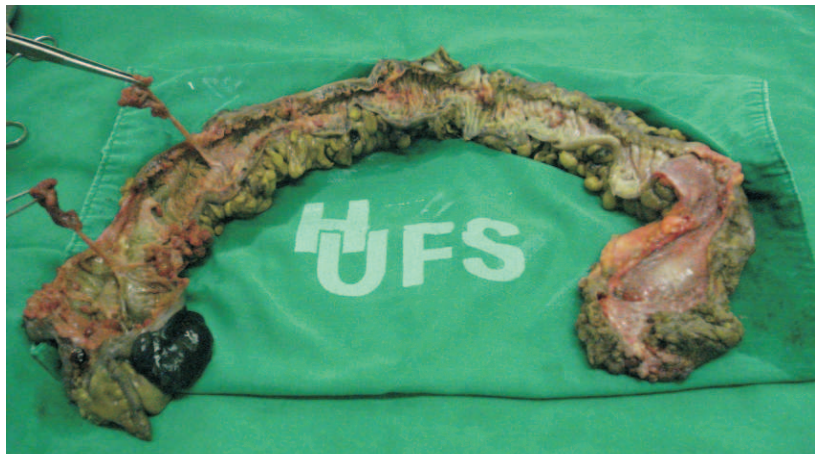

Figura 3 - Peça cirúrgica (intestino grosso + íleo terminal) da paciente 1 com presença de múltiplos pólipos. de baixo grau em mucosa colônica (03 lesões); e margens cirúrgicas proximal e distal livres de neoplasia (Figuras 4 e 5).

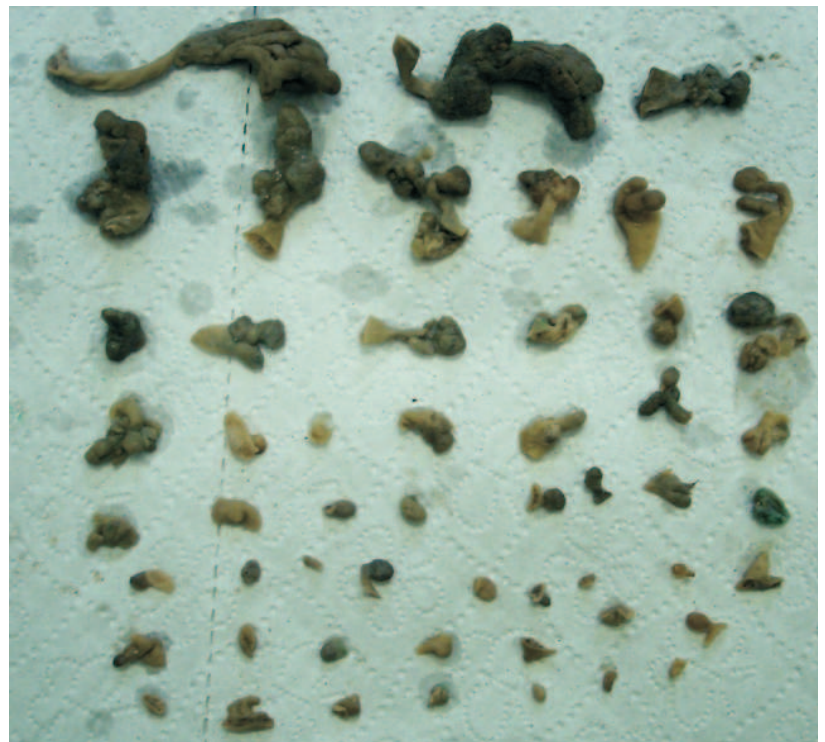

Figura 4- 53 pólipos retirados da peça cirúrgica da paciente 1. Os pólipos maiores exibem aspecto lobulado característico da Polipose Juvenil.

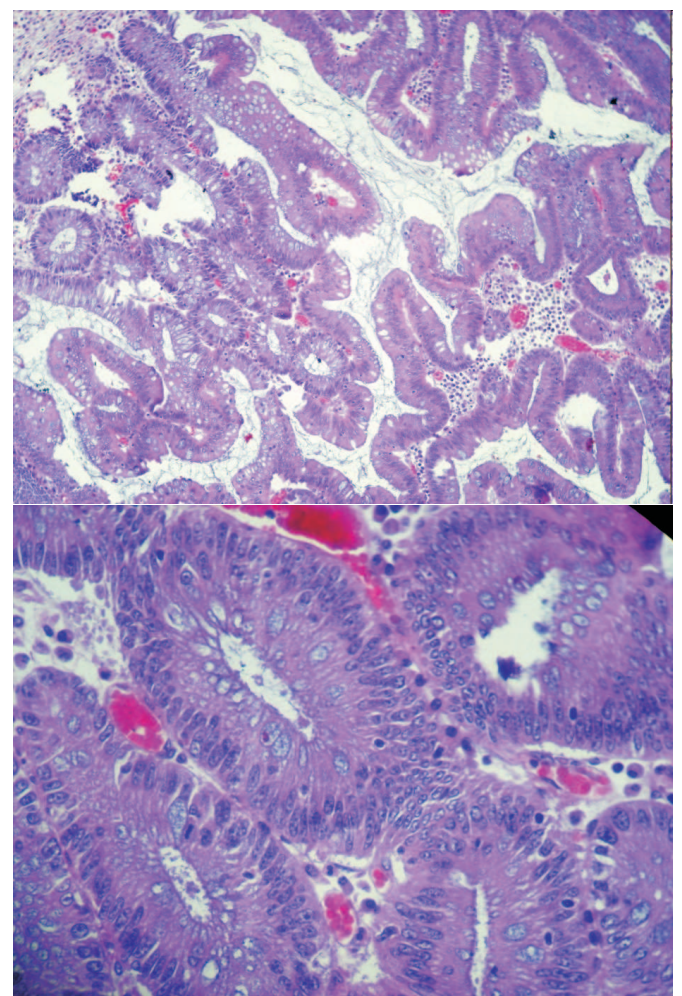

Figura 5 - Microscopia de um dos pólipos da peça cirúrgica da paciente 1. Em menor aumento, pólipo juvenil com área constituída por glândulas tortuosas e irregulares, revestidas por epitélio displásico. Em maior aumento, displasia epitelial caracterizada por núcleos atípicos, alongados, hipercromáticos e com pseudo-estratificação. 
Os aspectos clínicos e anatomopatológicos são, portanto, consistentes com Polipose Juvenil.

\section{Caso 2}

M.V.P.M., gênero masculino, 24 anos, estudante, relata sangramento retal e dificuldade para evacuar há 15 dias. Refere ardor anal mais intenso durante a evacuação e ausência de tumoração anal ou prolapso. Atualmente está com hábito intestinal de uma vez ao dia. Refere, também, tenesmo várias vezes ao dia terminando com sangramento retal.

Antecedentes Familiares: avô apresentou câncer de pulmão e pai é hipertenso.

No dia 16 de janeiro de 2009, o paciente foi submetido a uma colonoscopia (Figura 6) que evidenciou mais de 20 pólipos no cólon e no reto de tamanhos variados (entre 5 e $20 \mathrm{~mm}$ ). Vários pólipos foram excisados e 12 deles enviados para exame anatomopatológico.

O exame anatomopatológico dos 12 pólipos excisados evidenciou: 04 pólipos juvenis em mucosa do ceco e cólon ascendente (Figura 7); 03 adenomas tubulares com displasia de baixo grau em mucosa do ceco e cólons ascendente e descendente; e 05 adenomas com padrão serrilhado e displasia de baixo grau em mucosa do ceco, cólon ascendente, transverso, sigmóide e reto. $\mathrm{O}$ aspecto histológico das lesões polipóides displásicas (adenomatosas), que exibem freqüente dilatação cística, ramificação e tortuosidade de glândulas (aspecto hiperplásico/serrilhado), associado à presença de pólipos juvenis são consistentes com Polipose Juvenil.

Foi indicado o mesmo tratamento do caso 1 (proctocolectomia total restaurativa videolaparoscópica com anastomose íleo-anal e bolsa ileal em J com ileostomia protetora), mas, como o paciente não aceitou submeter-se à cirurgia e não apresentou displasia de alto grau, será feito acompanhamento com colonoscopia, exérese dos pólipos e estudo anatomopatológico dos mesmos. Surgindo displasia de alto grau ou fatores agravantes (como hemorragia, dor abdominal, prolapso, etc.) será insistido em realizar o tratamento cirúrgico.

\section{DISCUSSÃO}

Os pólipos juvenis foram descritos pela primeira vez em 1908 por Verse ${ }^{(4)}$; e podem ocorrer de forma isolada ou múltipla. Histologicamente, a lâmina própria

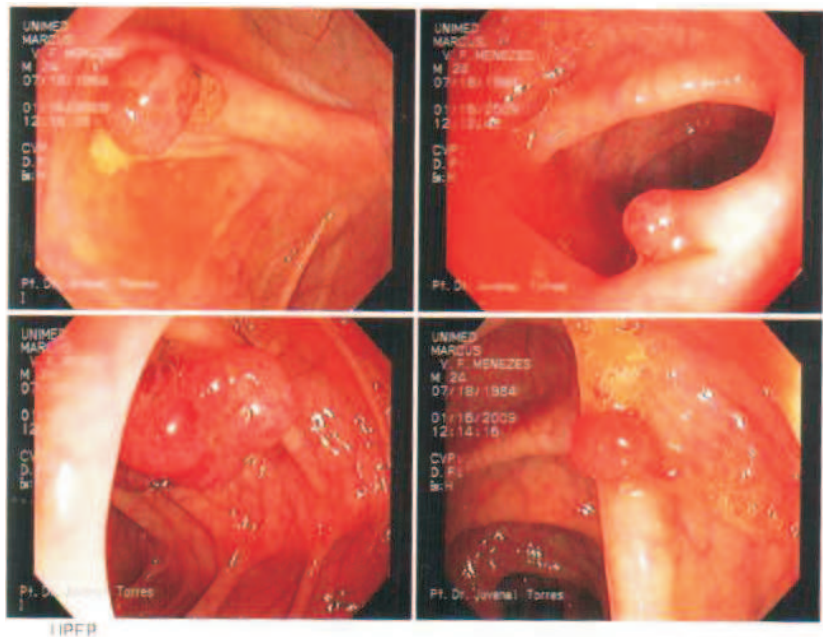

Figura 6 - Colonoscopia do paciente 2 mostrando alguns pólipos sésseis e pediculados no ceco.

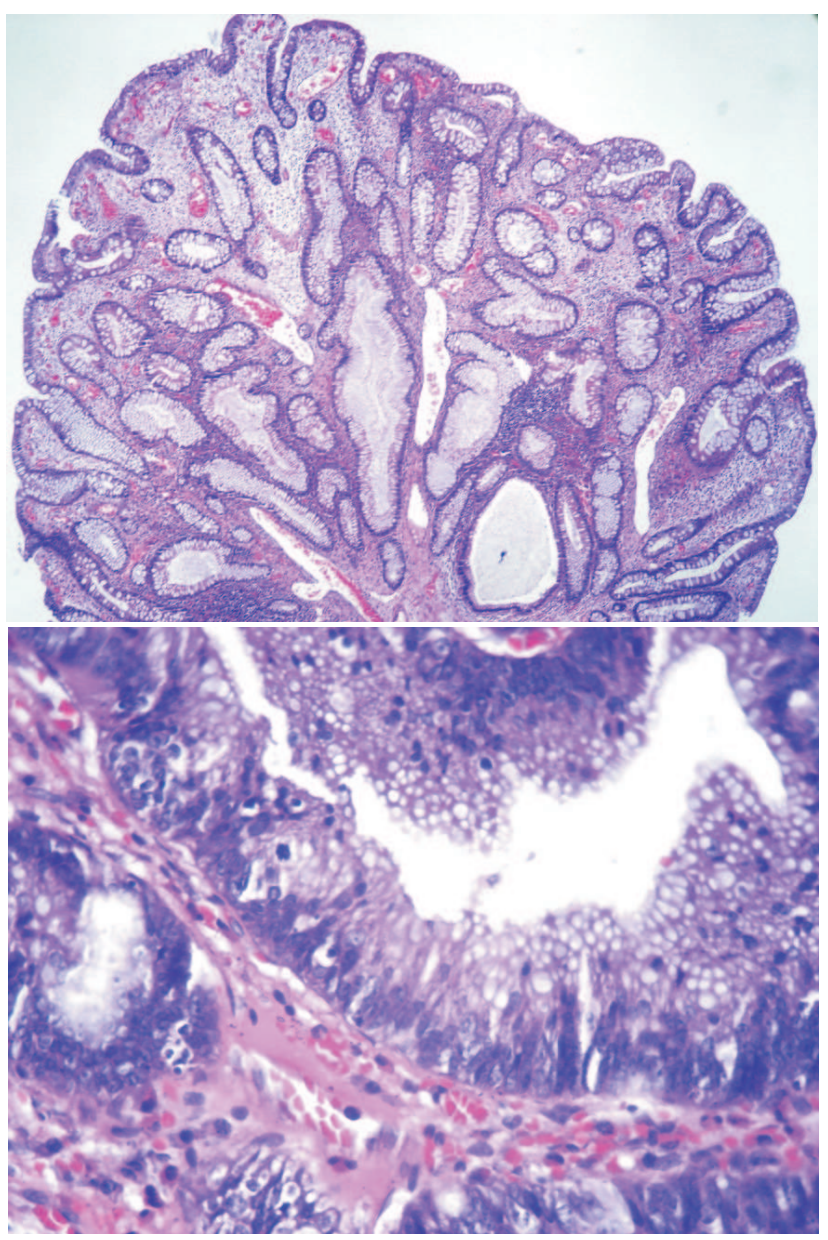

Figura 7 - Microscopia de um dos pólipos excisado durante a colonoscopia do paciente 2. Em menor aumento, pólipo juvenil com glândulas irregulares e cisticamente dilatadas. Em maior aumento, epitélio glandular pseudoestratificado com atipias de aspecto displásico (núcleos hipercrômicos e figuras de mitose). 
constitui a maior parte do pólipo, encerrando numerosas glândulas cisticamente dilatadas. A inflamação é comum e sua superfície pode estar congesta ou ulcerada. Em geral, são lesões isoladas e hamartomatosas sem potencial de malignidade. A manifestação clínica principal é o sangramento retal e a auto-amputação é o curso final da maioria desses pólipos ${ }^{(2)}$.

A Polipose Juvenil é uma condição incomum e foi primeiramente documentada por McColl e cols., em $1964^{(5)}$. Esta síndrome afeta de 1 em $100.000^{(6)}$ a $1 \mathrm{em} 160.000^{(7)}$ pessoas e costuma se manifestar entre 4 e 14 anos de idade. O seu diagnóstico é feito quando os seguintes critérios clínicos são encontrados ${ }^{(8)}$ : mais de 5 pólipos juvenis no cólon ou no reto, ou; pólipos juvenis em outras áreas do trato gastrintestinal, ou; qualquer número de pólipos juvenis e uma história familiar positiva. A paciente 1 preenche dois critérios: mais de 50 pólipos juvenis e história familiar positiva. Já o paciente 2 preenche somente um dos critérios: mais de 5 pólipos juvenis no cólon e no reto.

A Polipose Juvenil foi classificada por Sachatello et al ${ }^{(9)}$ em três subgrupos: 1) Polipose Juvenil da infância; 2) Polipose Juvenil colônica; 3) Polipose gastrintestinal juvenil generalizada. A Polipose Juvenil da infância está associada a sangramento gastrintestinal de repetição, prolapso retal e intussuscepção, que ocasionam a morte precoce dos pacientes. A Polipose Juvenil colônica é a forma mais comum; os pólipos localizam-se no cólon e os portadores têm um prognóstico bom. Na forma generalizada, a distribuição dos pólipos se assemelha à verificada na Síndrome de PeutzJeghers, mas a pigmentação da mucosa oral, lábios e dedos está ausente ${ }^{(10)}$. Dentro desta classificação ambos os pacientes são portadores da Polipose Juvenil colônica.

Os pólipos na Polipose Juvenil são hamartomatosos e variam de poucos milímetros a 5 $\mathrm{cm}$ de diâmetro. São revestidos por uma única camada de epitélio de células colunares, que frequentemente ulceram, levando à hemorragia e à infecção ${ }^{(1)}$. Esta característica associada ao achado de que a maioria dos pólipos grandes são pediculados, é responsável pela evolução natural e pelos sintomas recidivantes da polipose juvenil, que incluem hemorragia gastrintestinal, dor abdominal, obstrução intestinal, anemia, intussuscepção, prolapso, enteropatia perdedora de proteínas, desnutrição e auto-amputação dos pólipos. Manifestações extracolônicas incluem: macrocefalia, alopecia e fenda palatina. Nenhum dos pacientes apresentou manifestações extracolônicas.

A Polipose Juvenil é uma síndrome autossômica dominante e está associada à mutação do gene SMAD4 localizado no cromossomo $18 \mathrm{q} 21^{(11)}$. Em 2004, um total de 141 pacientes foram testados para mutação no gene SMAD4 em 6 estudos (Friedl et al. ${ }^{(12)}$, WoodfordRichens et al. ${ }^{(13)}$, Howe et al. ${ }^{(14,15)}$, Roth et al. ${ }^{(16)}$, Kim et al. $\left.{ }^{(17)}\right) 32(22,7 \%)$ pacientes apresentaram mutação positiva. Esta mutação provoca perda da inibição do crescimento celular e inibição da apoptose (alteração do fator de crescimento transformador beta - TGF â) com crescimento do componente mesenquimal o que resulta em displasia epitelial e progressão neoplásica (8). A perda dos receptores do TGF â ocorre, com frequiência, em tumores humanos, proporcionando uma vantagem proliferativa às células tumorais ${ }^{(1)}$. Devido a esta alteração a síndrome apresenta um potencial de malignização significante ${ }^{(11)}$.

Vários trabalhos na literatura relatam a ocorrência de câncer gastrintestinal em pacientes portadores de Polipose Juvenil. Howe et al. ${ }^{(18)}$ em 1998 mostrou que num grupo de 117 pessoas, 16 das 29 pessoas portadoras de Polipose Juvenil desenvolveram câncer gastrointestinal. Em 1999, Agnifili et al. ${ }^{(19)}$ realizaram uma revisão de literatura de 51 relatos de 12 países com um total de 271 pacientes portadores de Polipose Juvenil. A incidência de adenomas foi de 18,45\% (50 pacientes) e a de carcinomas foi de 17,34\% (43 pacientes), com distribuição equivalente entre os gêneros. Coburn et al. ${ }^{(20)} \mathrm{em} 1995$ examinaram 218 portadores da síndrome, destes, 36 (17\%) desenvolveram câncer gastrintestinal.

A paciente 1 apresentava alteração adenomatosa em pólipos do tipo juvenil com displasia de alto grau e história familiar de carcinoma colônico (tio falecido portador da mesma síndrome). O paciente 2 apresentou alteração adenomatosa com padrão serrilhado e displasia de baixo grau em pólipos juvenis. Ambos confirmam a teoria de Goodman et al. ${ }^{(21)}$ a qual sugere que a sequiência de transformações ocorre de pólipos juvenis para adenomas e, finalmente, câncer.

A mutação do gene SMAD4 também é responsável pelo caráter hereditário da Polipose Juvenil. No $1^{\circ}$ caso relatado neste trabalho, por exemplo, a herança familiar é fortemente positiva já que a paciente possui mãe, dois tios maternos e um primo portadores da síndrome. $\mathrm{O} 2^{\circ}$ caso não possui relato familiar. 
Os pacientes portadores da Polipose Juvenil devem ser acompanhados rigorosamente devido ao alto índice de recidiva dos pólipos. Exames endoscópicos e excisão dos pólipos encontrados devem ser realizados regularmente para regressão das manifestações clínicas e prevenção de transformações neoplásicas ${ }^{(4)}$. Quando os pólipos são numerosos e difíceis de controlar endoscopicamente, quando sintomas como, sangramento retal e diarréia são abundantes, ou quando há alguma suspeita de câncer colo-retal, os pacientes devem ser submetidos à cirurgia.

O tratamento cirúrgico indicado envolve colectomia total ou proctocolectomia total restaurativa com bolsa ileal ${ }^{(22)}$. A paciente 1 era portadora de um número muito grande de pólipos e um deles já com displasia de alto grau além de possuir história familiar de câncer colônico em tio portador da polipose juvenil, portanto, uma paciente com maior risco de malignização. Foi indicado o tratamento cirúrgico e a paciente foi submetida à proctocolectomia total restaurativa com anastomose íleo-anal com bolsa ileal em J. Já o paciente 2 como não aceitou submeter-se à cirurgia e não apresentou displasia de alto grau, foi indicado acompanhamento com colonoscopia, exérese dos pólipos e estudo anatomopatológico dos mesmos. Surgindo displasia de alto grau ou fatores agravantes (como hemorragia, dor abdominal, prolapso, etc.) será insistido em realizar o tratamento cirúrgico.
Mesmo após o procedimento cirúrgico, é indicado acompanhamento endoscópico em virtude da possibilidade de surgimento de outros pólipos no trato gastrintestinal restante. Um estudo realizado por Oncel et al. ${ }^{(22)}$ relata o acompanhamento de 10 pacientes portadores de Polipose Juvenil que foram submetidos à colectomia total ou proctocolectomia total restaurativa. Em nove anos, 5 dos 10 pacientes operados apresentaram recidiva dos pólipos, carcinoma do reto, ou ambos.

O tratamento medicamentoso da Polipose Juvenil ainda permanece controverso. Neste mesmo estudo, Oncel et al. ${ }^{(22)}$ administraram sulindac $(150 \mathrm{mg})$ em dois pacientes que foram submetidos à excisão endoscópica dos pólipos. Os dois pacientes não apresentaram recorrência dos pólipos durante dois anos (paciente 1) e nove anos (paciente 2). Sulindac é usado efetivamente em pacientes portadores de Polipose Adenomatosa Familiar para reduzir o número de adenomas no cólon ${ }^{(23,24)}$, e como sugere o estudo de Oncel et al. pode ser efetivo no controle dos pólipos em pacientes portadores de Polipose Juvenil.

A importância do relato dos casos de Polipose Juvenil se deve ao fato de ser uma patologia de ocorrência rara, implicar em tratamento agressivo para pacientes jovens, poder evoluir para câncer do trato gastrointestinal e ser relevante diagnóstico diferencial com outras síndromes polipóides.

\footnotetext{
ABSTRACT: Juvenile Polyposis Syndrome is a rare disease and is included in the Hamartomatous Familial Polyposis's (HFP) group. It's an autosomal dominant syndrome which can be determinated by SMAD4/DPC4 germline mutations (which codifies an intermediary mediator of TGF- $\beta$ ). It's characterized by 10 or more hamartomatous polyps (juveniles) throughout the gastrointestinal tract, especially in the colon. The symptoms usually appears between the ages of 4 and 14 years old. Some polyps can acquire adenomatous changes despite the lesion's hamartomatous nature and there's chance of colorectum malignization. Case report of two patients with Juvenile Polyposis coli associated to adenomatous changes with dysplasia and literature review.
}

Key words: Juvenile Polyposis Syndrome, malignization, familiar inheritance.

\section{REFERÊNCIAS}

1. Hamilton S.R., Aaltonen L.A. (Eds.): World Health Organization Classification of Tumours. Pathology and Genetics of Tumours of the Digestive System. IARC Press:Lyon 2000.

2. Marigo C, Medeiros ML, Maluf FC - Pólipos e Polipose Juvenil: estudo epidemiológico e histopatológico de 45 casos. Rev Bras ColoProct 1994; 14(2): p 92-95.
3. Calache J, Barbieri D, Maksoud J - Papel da colonoscopia nas afecções colo-retais na infância. Pediat 1986; 8: p 148-157.

4. Pinotti HW. Tratado de Clínica Cirúrgica no Aparelho Digestivo. Vol. 2. São Paulo: Atheneu, 1994. p.1254-1256.

5. McColl IBH, Veale AM, Morson BC - Juvenile Polyposis Coli. Proc. R. Soc. Med 1964; 57: p 896-7.

6. Burt RW, Bishop DT, Lynch HT, Rozen P, Winawer SJ - Risk and surveillance of individuals with heritable factors for colorectal cancer. WHO Collaborating Centre for the 
prevention of colorectal cancer. Bull. World Health Organ.1990; 68: p 655-65.

7. Chevrel J-PAJ, Gueraud J-P - Trois cas familiaux de polypose juvenile. Chirurgie 1975; 101: p 708-21.

8. Jass JR, Williams CB, Bussey HJ, Morson BC - Juvenile polyposis-a precancerous condition. Histopathology 1988; 13: p 619-30.

9. Sachatello CR, Hahn IS, Carrington CB - Juvenile gastrointestinal polyposis in a female infant: report of a case and review of the literature of a recently recognized syndrome. Surgery 1974; 75: p 107-14.

10. Coelho JCU, Moraes LM, Ribeiro AB, Pinotti R - Polipose Juvenil do trato gastrintestinal. Rev Bras ColoProct 1987; 7(3): p 104-106.

11. Chow E, Macrae F - Review of Juvenile Polyposis Syndrome. J Gastroenterol hepatol 2005; 20: p 1634-1640.

12. Friedl W, Uhlhaas S, Schulmann K et al.- Juvenile polyposis: massive gastric polyposis is more common in MADH4 mutation carriers than in BMPR1A mutation carriers. Hum. Genet. 2002; 111: p 108-11.

13. Woodford-Richens K, Bevan S, Churchman M et al - Analysis of genetic and phenotypic heterogeneity in juvenile polyposis. Gut 2000; 46: p 656-60.

14. Howe JR, Roth S, Ringold JC et al - Mutations in the SMAD4/ DPC4 gene in juvenile polyposis. Science 1998; 280: p 10868.

15. Howe JRSM, Ahmed AF, Ringold J et al.- The prevalence of MADH4 and BMPR1A mutations in juvenile polyposis and absence of BMPR2, BMPR1B, and ACVR1 mutations. J. Med. Genet. 2004; 41: p 484-91.

16. Roth $\mathrm{S}$, Sistonen $\mathrm{P}$, Salovaara $\mathrm{R}$ et al.- SMAD genes in juvenile polyposis. Genes Chromosomes Cancer 1999; 26: p 54-61.

17. Kim IJKJ, Yoon KA, Heo SC et al.- Germline mutations of the dpc4 gene in Korean juvenile polyposis patients. Int. J. Cancer 2000; 86: p 529-32.
18. Howe JR, Mitros FA, Summers RW - The risk of gastrointestinal carcinoma in familial juvenile polyposis. Ann.Surg. Oncol. 1998; 5: p 751-6.

19. Agnifili A, Verzaro R, Gola P et al. - Juvenile polyposis: case report and assessment of the neoplastic risk in 271 patients reported in the literature. Dig. Surg. 1999; 16: p 161-6.

20. Coburn MC, Pricolo VE, DeLuca FG, Bland KI - Malignant potential in intestinal juvenile polyposis syndromes. Ann Surg Oncol 1995; 2: p 386-91.

21. Goodman ZD, Yardley JH. Milligan FD - Pathogenesis of colonic polyps in multiple juvenile polyposis. Cancer 1979; 43: $\mathrm{p}$ 1906-1913.

22. Oncel $\mathrm{M}$ et al. - Colonic Surgery in Pacients with Juvenile Poliposis Syndrome: a case series. Dis Colon Rectum 2005; 48: p 49-56.

23. Guldenschuh I, Hurlimann R, Muller A et al - Relationship between APC genotype, polyp distribution, and oral sulindac treatment in the colon and rectum patients with familial adenomatous polyposis. Dis Colon Rectum 2001; 44: p 10909.

24. Phillips RK, Wallace MH, Lynch PM, et al - A randomized, double blind placebo controlled study of celecoxib, a selective cyclooxigenase 2 inhibitor, on duodenal polyposis in familial adenomatous polyposis. Gut 2002; 50: p 857-60.

\section{Endereço para correspondência:}

JUVENAL DA ROCHA TORRES NETO

Rua Ananias Azevedo No. 100, apto. 902

Bairro Praia 13 de Julho

Aracaju-SE

E-mail: jtorres@infonet.com.br

Tel.(fax).: (79) 32144830 